\title{
Alcohol and Illegal Drug Use Behaviors and Prescription Opioids Use: How Do Nonmedical and Medical Users Compare, and Does Motive to Use Really Matter?
}

\author{
Lilian A. Ghandour ${ }^{a}$ Donna S. El Sayed ${ }^{a}$ Silvia S. Martins ${ }^{b}$ \\ a Department of Epidemiology and Population Health, American University of Beirut, Beirut, Lebanon; \\ ${ }^{b}$ Department of Mental Health, Johns Hopkins University, Baltimore, Md., USA
}

\section{Key Words}

Prescription opioids $\cdot$ Nonmedical use $\cdot$ Self-medication •

Illegal drugs $\cdot$ Alcohol $\cdot$ Lebanon

\begin{abstract}
Background/Aims: This study compares illegal drug and alcohol use behaviors between medical and nonmedical users of prescription opioids $(\mathrm{PO})$ and nonmedical users with distinct motives to use. Method: An ethically approved crosssectional study (2010) was conducted on a representative sample of private university students $(n=570)$, using a selffilled anonymous questionnaire. Results: About $25 \%$ reported using PO only medically and $15 \%$ nonmedically. The prevalence of alcohol and illegal drug use was consistently higher among nonmedical than medical PO users. Adjusting for age and gender, lifetime medical users of $P O$ were more likely to use marijuana only ( $\mathrm{OR}=1.8,95 \% \mathrm{Cl}: 1.1,2.8$ ), while nonmedical users were at higher odds of using marijuana, ecstasy, cocaine/crack, and alcohol problematically. Compared to nonusers, students who took PO nonmedically for nontherapeutic reasons were more likely to use various illegal drugs, but nonmedical users who took PO to relieve pain/ help in sleep were only more likely to use marijuana (OR = $2.5,95 \% \mathrm{Cl}: 1.1,5.4)$ and alcohol (e.g. alcohol abuse; $\mathrm{OR}=3.8$,
\end{abstract}

$95 \% \mathrm{Cl}:=1.4,10.1)$. Conclusion: Youth who use PO nonmedically to self-treat have a different alcohol and illegal drugusing profile than those who take it for nontherapeutic reasons.

Copyright $\odot 2013$ S. Karger AG, Basel

\section{Introduction}

Nonmedical use of prescription opioids (PO) continues to pose a major public health concern and a societal burden, particularly in the U.S., given the medication's rather high and increasing prevalence, addictive potential, and dangerous contraindications and interactions with alcohol, illegal drugs, and other medicines. $\mathrm{PO}$ are the most common psychoactive prescription drugs used nonmedically [1-4] and the second most prevalent substance used among youth in the U.S., following marijuana $[5,6]$. Young adults especially (aged $18-25$ years) have been shown to be most vulnerable to $\mathrm{PO}$ use [5-7]. Though much of the evidence stems from North Ameri$\mathrm{ca}$, a recent United Nations panel declared the issue of prescription drug abuse as a global health concern, potentially exceeding that of illegal drug use [8].

\section{KARGER}

E-Mail karger@karger.ch

www.karger.com/ear
(C) 2013 S. Karger AG, Basel

$1022-6877 / 13 / 0194-0202 \$ 38.00 / 0$
Lilian A. Ghandour, $\mathrm{PhD}, \mathrm{MPH}$

Department of Epidemiology and Population Health Faculty of Health Sciences, American University of Beirut Riad El-Solh, PO Box 11-0236, Beirut 1107-2020 (Lebanon) E-Maillg01@aub.edu.lb 
PO users are either medical users who have been prescribed the medication by a doctor, and/or nonmedical users, a classification that has typically included those who take the medication without a doctor's prescription, for periods longer than prescribed, or for reasons other than medication's intended purpose (e.g. 'to experiment' or 'to get high') [3, 4]. Medical use of prescription drugs in general, opioids in particular, has been on the rise in the U.S. $[9,10]$. While PO use is fundamental and highly efficacious for the treatment of acute and chronic pain, fears of diversion and consequently nonmedical use of these medications have necessitated and justified the close monitoring of prescribed PO use. Studies from North America have linked nonmedical use with an increased likelihood of using alcohol or illegal drugs $[4,6$, 11-14]. Nonetheless, we believe that classification of nonmedical use as it stands is too nonspecific since it combines various heterogeneous notions of legality (i.e. without a doctor's prescription), tolerance (i.e. long duration of use), diversion (i.e. prescribed for somebody else), and motivation to use (e.g. to get high). Clearly the definition puts a heterogeneous group of nonmedical users under the umbrella of 'nonmedical users' and while they all represent 'nonprescribed users' indeed, clearly their motives could vary from self-treatment to getting high, to a combination of both.

Only recently have one group of U.S. researchers examined subtypes of nonprescribed PO use, revealing that nonmedical users with motives other than self-medication have an increased risk of alcohol and illegal drug use, whereas users taking opioids nonmedically but for their intended purpose were similar in their other substanceusing profile to those who never used $\mathrm{PO}$ nonmedically $[14,15]$. Given the heterogeneity of motives among nonmedical PO users and the possibility of diversion from medical to nonmedical use, it becomes important therefore to compare medical users to nonmedical users with regards to their other substance use behaviors, including alcohol and illegal drugs. It is also imperative to further explore any differences within the nonmedical users, particularly those who take PO with the intention to selftreat versus those who use these medications for other nontherapeutic reasons, such as to counteract the effects of illegal drugs or get high. Understanding these distinctions carries clear and meaningful implications for prevention as well as the clinical management of PO users since harmful side effects are likely to occur when $\mathrm{PO}$ are used with other illegal drugs and/or alcohol. For instance, $\mathrm{PO}$ used in combination with depressant drugs (e.g. alcohol) enhances opioids' toxicity and may even result in death. Overall, combining opioids with other drugs is much more deleterious than taking opioids alone [16].

Considering the implications of such data, and the fact that the entire published literature on PO is primarily produced in the U.S. $[6,12,15,17]$ and Canada [18-20], there is a clear need to begin exploring such issues in other non-Western countries. North American researchers have themselves recognized and criticized this gap in the literature, stressing the need to examine the issue outside their region to enable cross-national comparisons [1, 21]. In Europe, while published studies report on the medical consumption of PO using national databases [22, 23], data on the nonmedical use of prescription drugs is unavailable. Similarly, epidemiological data investigating nonmedical use of psychoactive prescription medications in Arab and Middle Eastern countries, including Lebanon, were also nonexistent until recently [24]. Absence of data, however, does not translate or mean lack of a problem since the recent and only survey from Lebanon suggests that the issue of nonmedical use of prescription drugs warrants close monitoring among university students [24]. In this survey, as is the case among North American campuses [12, 25], POs were the most commonly used prescription drug, both medically (36.9\%) and nonmedically (15.1\%) [24]. Quite interestingly, the percentage of students reporting nonmedical use of any prescription drug (21.6\%) exceeded that of lifetime marijuana use (19.38\%), confirming a recent United Nations declaration [8].

Noteworthy are Lebanon's particularities that play an influential role in the country's pharmacoepidemiological situation, including the availability of prescription medications such as opioids. Though online purchasing is uncommon and public advertising and marketing of medications is prohibited by the Lebanese Ministry of Public Health [26], other contextual factors including the occasional political instability, wars, and internal strife may have increased and continue to influence the likelihood of self-medication. Such adverse events have also often impeded the government from enforcing pharmacy sales' regulations [27], as evidenced by the latest survey data whereby pharmacists were reported as one of the main sources of obtaining PO nonmedically (49\% of the students listed it as a source for their nonprescribed PO use) [24]. Irrespective of the source, PO seem to be effortlessly accessible since almost two thirds (63.4\%) of the university students reported that it would be easy/very easy for them to obtain PO without a prescription [24]. Achieving the balance between making $\mathrm{PO}$ available to those in pain versus preventing the med- 
ication's abuse and diversion is a global as well as a local challenge. In Lebanon, and according to the latest Report of the International Narcotics Control Board on the Availability of Internationally Controlled Drugs [28], the average daily consumption of opioid analgesics is much lower than that of Western countries, but has doubled between 1997-1999 and 2007-2009. While national statistics on medical diversion are unavailable, survey data suggest that the phenomenon does exist; about 15\% of the PO medical users in the survey reported having been approached to sell, trade, or give away their medication [24].

The aim of the present paper therefore is to (1) compare the prevalence and odds of alcohol and illegal drug use between medical and nonmedical users of PO and, furthermore, between (2) nonmedical PO users with the intention to self-treat and nonmedical PO users with other nontherapeutic motives, such as to experiment or get high, using a sample of undergraduate and graduate private university students from Lebanon.

\section{Methods}

\section{Participants}

Graduate and undergraduate university students attending a large private university in Beirut (Lebanon) were surveyed in May 2010, after obtaining Institutional Review Board ethical approval. The university follows an American educational approach, and caters to nationals from all over Lebanon, as well as regional and international students. The sample was selected using a proportionate two-stage stratified cluster sampling technique to ensure representation of all faculties and levels of education (undergraduate/graduate). Of the classrooms (clusters) selected, $52.2 \%$ of the professors agreed to participate, $9 \%$ refused, and $38.8 \%$ did not respond despite several contact attempts. Student cooperation rate among the participating classrooms was $86 \%$, resulting in a total sample of 570 students. All analyses were weighted by faculty and educational level to account for the incomplete response rate and guarantee representation of all faculties.

\section{Instrument and Measures}

Participating students filled out a self-report anonymous questionnaire in English, the primary method of report in all U.S. major drug use surveys [7,29]; the survey was conducted during class hours while avoiding all major examination periods. Students read and agreed to an informed written consent form that described the objectives of the study, the survey's anonymity (absence of personal identifiers) and confidentiality (availability of data to research team only), and their right to refuse participation or answer any question.

Common demographic questions were assessed: gender, age, nationality, marital status, and living arrangement. Self-reported socioeconomic status was also measured using this question: 'Compared to other people your age, how well-off do you think you/your family is?'; responses included: a little/ lot poorer than most, about the same as most, a little/ lot richer than most. It is worth noting that for the most part in Lebanon, university students' self-assessed socioeconomic status is a reflection of their parents'.

\section{PO Use}

To increase identification and reduce information errors, brand name PO available on the market were used as examples. Since different terminologies preclude cross-national comparisons, this study used the exact definitions (following author permission) employed in the only other college survey examining motives to use among nonmedical users [15, 30, 31]. Lifetime medical use of $\mathrm{PO}$, or use based on a doctor's prescription, was assessed as follows: 'Based on a doctor's prescription, have you ever taken any pain medication (e.g. DiAntalvic ${ }^{\circledR}$, Vicodin $^{\circledR}, \mathrm{Da}-$ falgan Codeine ${ }^{\circledR}$, Tramal $^{\circledR}$, and other)?'; a past-year measure was also included. A separate question assessed nonmedical use of PO (both lifetime and past-year), which was defined as using PO that were prescribed for somebody else, for longer periods than prescribed, or for reasons other than what the medication is intended for (e.g. to get high) $[13,25,31,32]$. Nonmedical users were then asked to report the various reasons/motives for their nonprescribed use; more than one response could have been reported (i.e. relieve pain, help sleep, decrease anxiety, experiment, get a high feeling, counteract effect of other drugs, safer than street drugs).

Mutually exclusive groups of PO users (lifetime and past-year) were created including: (1) no medical or nonmedical use (i.e. nonuse of PO, $\mathrm{n}=312)$, (2) medical PO use only $(\mathrm{n}=158)$, and (3) any nonmedical PO use $(\mathrm{n}=89)$ including nonmedical PO users only $(\mathrm{n}=22)$ as well as both medical and nonmedical users $(\mathrm{n}=$ 67).

Using the variable measuring 'motivation to use the medication', another measure of PO use was created as such: (1) never nonmedical users, (2) nonmedical users who used PO for its intended purpose only (i.e. to relieve pain or help in sleep, $n=72$ ), and (3) nonmedical users who used it for other reasons (may include pain relief, $\mathrm{n}=10$ ); 7 nonmedical users did not report on their reasons for PO use.

\section{Alcohol and Drug Use}

Students who reported any past-year alcohol use (more than just a sip or two) were asked about frequency of use, heavy episodic drinking, and DSM-IV-defined alcohol abuse. Frequency of alcohol use was assessed with the question, 'On average, in the past 12 months, how often did you have an alcoholic drink (more than just a few sips)?'(almost every day, 3 or 4 days a week, 1 or 2 days a week, 1 or 3 days per month, or less than once per month); frequent use was defined as drinking ' 1 or 2 days per week or more'.

Respondents who reported having had four or more alcoholic drinks in a row at least once in the preceding year were labeled 'heavy episodic alcohol users'. Students who drank once or more per month in the past-year were asked about alcohol-related problems (as per DSM-IV criteria for abuse), including frequent interference with work/university or negligence of university/work/ home responsibilities, serious and frequent/repeated arguments or problems with friends/family/neighbors, continued drinking despite alcohol-related problems, being under the influence in 
Table 1. Weighted lifetime and past-year prevalence of PO, alcohol, and illegal drug use measures in the student sample $(\mathrm{n}=570)$

\begin{tabular}{|c|c|c|c|c|c|c|}
\hline & \multicolumn{3}{|l|}{ Lifetime } & \multicolumn{3}{|l|}{ Past-year } \\
\hline \multicolumn{7}{|l|}{$\mathrm{PO}$} \\
\hline Nonusers & 58.86 & 312 & & 77.50 & 353 & \\
\hline Medical users only & 26.02 & 158 & $2.80(11)$ & 14.22 & 69 & $17.99(106)$ \\
\hline Any nonmedical use & 15.12 & 89 & & 8.28 & 42 & \\
\hline Any ecstasy & 2.79 & 14 & $2.89(16)$ & 1.28 & 5 & $3.10(17)$ \\
\hline Any crack/cocaine & 1.61 & 11 & $2.61(14)$ & 0.54 & 3 & $2.86(16)$ \\
\hline \multicolumn{7}{|l|}{ Alcohol } \\
\hline Any use & not assessed & & & 55.53 & 300 & $2.12(12)$ \\
\hline Frequent use & not assessed & & & $25.13^{1}$ & 133 & $2.48(14)$ \\
\hline
\end{tabular}

Medical use defined as use based on a doctor's prescription note. Nonmedical use defined as use without a doctor's prescription note or for longer periods than prescribed or for reasons other than what the medication is intended for.

${ }^{1} 45.38 \%$ among past-year alcohol users. ${ }^{2} 65.61 \%$ among past-year alcohol users. ${ }^{3} 39.08 \%$ among past-year alcohol users.

physically dangerous situations (e.g. driving), and having been arrested or stopped by the police more than once because of drinking/drunken behaviors. Alcohol abuse was defined as reporting one or more of the aforementioned problems. Lifetime and past-year use of illegal substances including marijuana, ecstasy, and cocaine/crack were also measured.

\section{Data Analyses}

Using Stata 12 MP [33], descriptive statistics, Pearson's $\chi^{2}$ test, and unadjusted and adjusted (controlling for the two universal confounders age and gender) binary logistic regression models were run. Complex survey data were used to account for sampling weights and the primary sampling unit (i.e. classroom). List-wise deletion was used in regression models in case of missingness $(<5 \%$ in most cases). The $\alpha$ level was set at 0.05 .

\section{Results}

\section{Sample Demographic Characteristics}

The final weighted sample included slightly more females (51.6\%); average age of the students was 19.9 years $(\mathrm{SD}=0.08)$. Most were Lebanese $(60.4 \%), 26.9 \%$ held 'dual citizenship', and about $13 \%$ were nonnationals. The majority had no romantic partner (87.9\%), and predominantly lived at home with their parents or family (spouse/ children) (73.6\%). About 60\% perceived themselves as 'well off as others their age', 10\% 'a little/lot poorer', and $30 \%$ 'a little/lot richer'.

Alcohol and Illegal Drug Use Behaviors and PO Use

\section{Estimates of PO and Other Substance Use}

Table 1 presents the weighted lifetime and past-year estimates of PO use, as well as alcohol and illegal drug use. Mutually exclusive groups of PO users (lifetime and pastyear) revealed that very few were nonmedical users only (3.75\%, $\mathrm{n}=22$, and $2.53 \%, \mathrm{n}=14$, respectively); thus, university students who reported using PO only nonmedically were combined with those having used PO both medically and nonmedically (i.e. any nonmedical users; table 1). Further analyses also showed that the majority of the lifetime nonmedical users had used $\mathrm{PO}$ without a prescription to self-medicate only $(87.5 \%, \mathrm{n}=72)$; the remaining percentage of students reported taking PO for other reasons (e.g. experimentation, getting high, counteracts other drugs) with or without its intended purpose.

\section{Lifetime and Past-Year Associations between PO, Alcohol, and Illegal Drugs}

Table 2 shows that the prevalence of lifetime use of alcohol and drugs was consistently highest among nonmedical users; moreover, the odds of using all substances (except lifetime marijuana) were comparable among nonPO users and those who used PO only medically in their lifetime (table 2). In contrast, nonmedical users (including nonmedical users only and those who reported both types of use) were at increased odds of using all substances, adjusting for age and gender (table 2). 
Similarly, past-year medical users of PO only were not any different from nonusers with regard to their odds of past-year alcohol or past-year illegal drug use (table 3). However, any nonmedical past-year PO use was strongly associated with past-year marijuana use, frequent alcohol use, and DSM-IV-defined alcohol abuse (table 3). The small number of past-year ecstasy and cocaine/crack use ( $n=5$ and 3 , respectively) impeded their inclusion in such analyses (table 1).

\section{Differential Role of Motives to Use among Nonmedical PO Users}

Subtypes of lifetime nonmedical users of $\mathrm{PO}$ were further defined by their motivation to use the drug nonmedically. Compared to those who had never used PO nonmedically, the prevalence of each of the alcohol and illegal drug measures was consistently higher in students who reported using PO nonmedically but for its intended medical purpose only, and highest in PO users for other motives (table 4); these trends were statistically significantly different in the case of lifetime marijuana use, cocaine/crack, and past-year heavy episodic drinking.

When compared to those who did not report any nonmedical use of PO, both the self-treatment and other motives groups showed a higher odds of lifetime use of marijuana, though much higher for the latter, adjusting for age and gender. This was only true for marijuana; nonmedical PO users who reported using the medication only for its intended purpose were as likely as nonusers to use ecstasy or cocaine/crack. On the contrary, nonmedical PO users who reported taking the medication for other motives were at significantly higher odds of all illegal drug use, controlling for age and gender (table 4).

With regard to alcohol, PO users who used the nonprescribed drug to self-treat (vs. no nonmedical use) were more likely to report frequent alcohol use, heavy episodic drinking, and alcohol abuse, but no statistically significant associations were observed between past-year alcohol use measures and other motives to nonmedically use PO (table 4).

\section{Discussion}

This study, the first of its kind from an Arab region, makes several contributions to the literature on PO: (1) it highlights the potential presence of a problem among college youth in Lebanon, which needs to be further investigated; (2) it underscores the strong association between nonmedical use of $\mathrm{PO}$ and alcohol and drug-related prob- lems, particularly in the case of nonmedical use for a nonintended purpose (or nontherapeutic motive); and (3) it confirms recent U.S. findings among college youth despite the different cultural and educational backgrounds.

In this sample of university students, PO users (compared to non-PO users) are at an increased odds of frequent and problematic alcohol consumption as well as illegal drug use; this was not the case for students who reported using PO only medically (i.e. as prescribed). Within nonmedical users, those who used PO for nontherapeutic reasons (compared to students who never used PO nonmedically) were more likely to report illegal drug use, corroborating recent findings by McCabe et al. [15, 34]. The self-treatment group in our sample was at higher odds of only marijuana use (compared to never nonmedical users) and to a lesser extent than nonmedical users using PO for nontherapeutic purposes [15, 34]. Quite interestingly, and contrary to other published findings, our study portrayed a different relation with alcohol; those in the self-treatment group (vs. never nonmedical users) were more likely to use alcohol frequently and experience alcohol-related problems. This was not the case for nonmedical users using PO for nontherapeutic reasons. Whether the self-treatment group within nonmedical users were ingesting both substances (PO and alcohol) to relieve their pain and help them sleep, or to self-treat anxiety symptoms, or even for other reasons, remains to be determined. The underlying mechanisms and temporal ordering of these behaviors clearly warrant further investigation given their implication on prevention and clinical management of these PO users. It is possible that either or both mechanisms of 'self-medication' and/or 'underlying genetic liability' to use both substances are at work [35-38].

Overall, the study findings underscore the importance of investigating 'motives to use' among nonmedical users as not all nonmedical users seem to be the same. It is possible that nonmedical users who take PO for reasons other than self-treatment experience greater odds of illegal drug use as part of an overall 'problem behavior syndrome' [39]; accordingly, the clinical management of these individuals should be different than that of PO users who ingest the medication nonmedically only to selfmedicate and relieve pain; the fact that some nonmedical users may do so in combination with alcohol also warrants further attention. Self-medication is not a risk-free behavior since nonmedical users who self-treat do not receive any medical counseling or information, and as such may be unaware of undesirable side effects, contraindications with other medications, or dangerous interactions with other substances. 


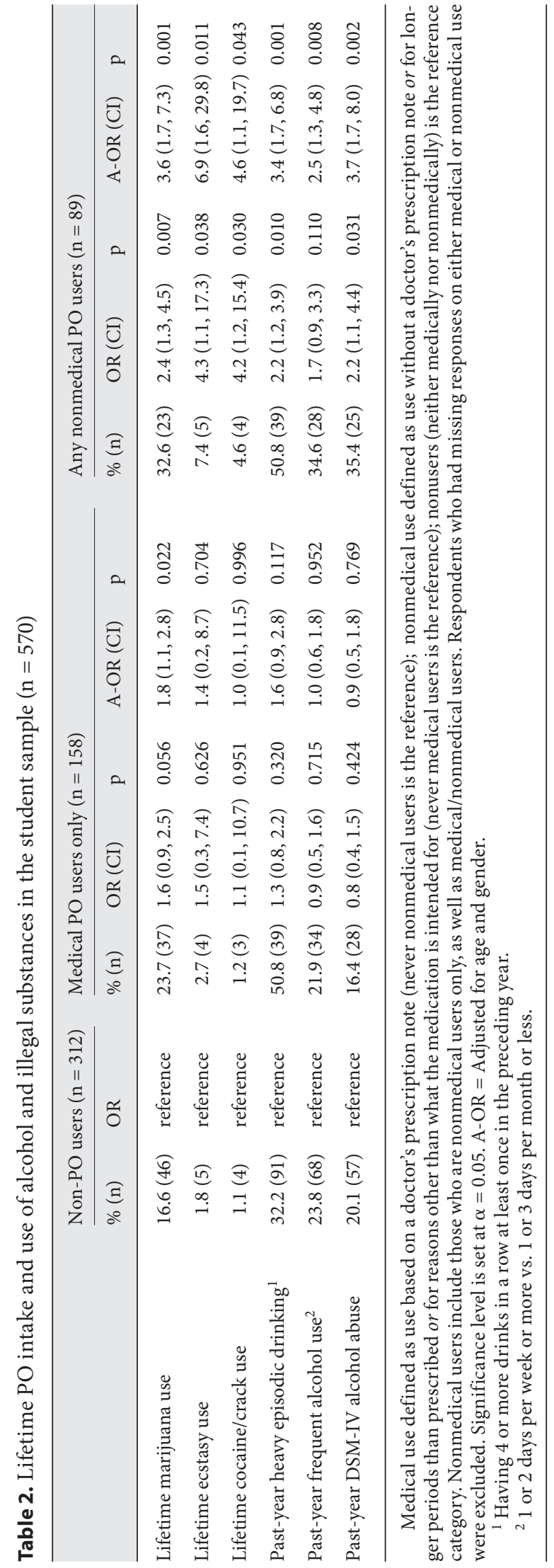

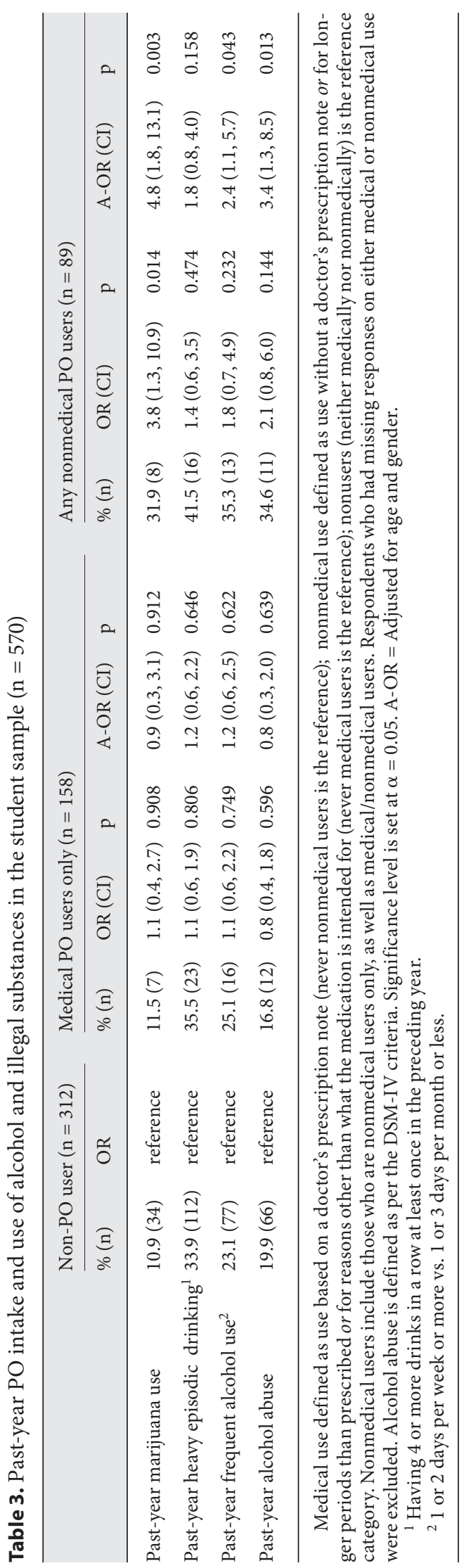




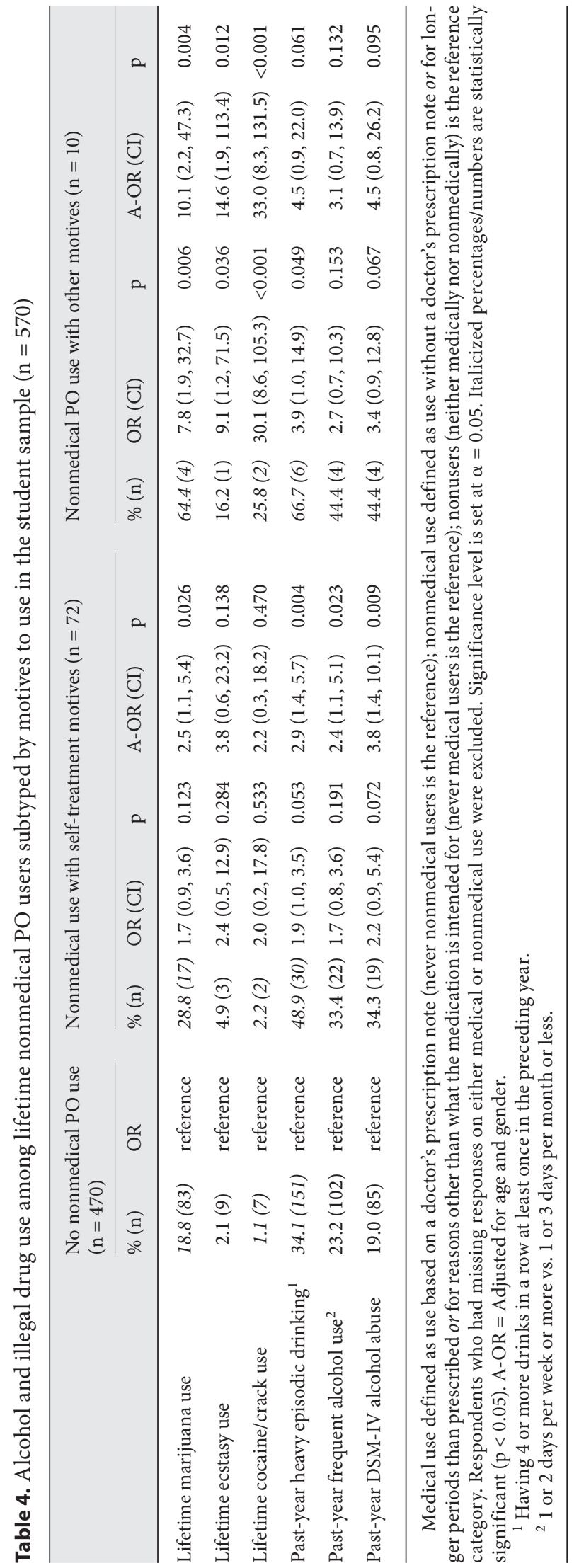

Despite their importance, these findings need to be considered in light of some limitations, beginning with our inability to make any conclusive remarks about the temporality of the observed behaviors as is the case with all cross-sectional studies. Second, we are careful about generalizing the situation to other university students or noncollege youth despite the university's heterogeneous student population. The replicability, however, of U.S. findings within the Lebanese context may suggest that the picture may not be much different on other Lebanese campuses. Third, while brand names available on the Lebanese market were used to exemplify what was meant by psychoactive PO (vs. over-the-counter pain medication), the medication list was not comprehensive, which may have introduced nondifferential information bias, specifically underestimating the overall prevalence of medical and nonmedical PO use. Moreover, examples included prescription medications of varying abuse potentials (i.e. Vicodin is a schedule III drug, DiAntalvic is schedule IV, Dafalgan Codeine is schedule II, and Tramal is a nonscheduled prescription drug), but all should not have been obtained or taken without a health professional's prescription since self-medication is not entirely risk free [40]. Fourth, very few reported using ecstasy and crack/cocaine which resulted in wide confidence intervals when analyzed. Fifth, we could not adjust for potential confounding influences of other illegal drugs in the marijuana models due to the small number of ecstasy and crack/cocaine users; moreover, since only past-year measures of alcohol were included, the latter was not adjusted for in models assessing relationship between lifetime PO and lifetime illegal drug use.

Compared to what is known about other drugs, data on PO use from the Arab world and the Middle East remains nonexistent, which impedes making any intraregional comparisons. Still, the present study generated evidence corroborating international findings, which suggests that this part of the world may not have escaped the problem of PO facing youth in the U.S. and Canada today. To our knowledge, no other published study from the region, at least from Lebanon, has incorporated both questions on medical and nonmedical PO use, which stresses the need to begin addressing this issue in-depth both locally and regionally. This is particularly important considering that alcohol and illegal drug use is an issue among youth in Lebanon [41, 42]. Future research directions could include investigating a larger more diverse sample of young adults or adolescents, exploring gender differences, and examining concurrent versus simultaneous use (i.e. coingestion) of PO. Examining context-spe- 
cific correlates such as exposure to wars and internal strife, as well as the irregular political instability, would be important and informative. In the present study, we attempted to explore such associations by including measures on exposure to any of the latest war-related events and/or political instability [e.g. assassination of the Lebanese Prime Minister in 2005, July 2006 war, and random bombings (2005-2008)], but no significant associations were observed, possibly due to the incomprehensiveness of the war exposure measures or the absence of a PTSD (post-traumatic stress disorder) diagnosis; after all, these young adults may have been involved in rescue efforts and/or may have been part of an active political party, or perhaps represented a segment of the population that is less likely to be affected (vs. children and/or older adults). Taking PO or other medications to cope with adverse events needs to be addressed in future studies, considering anecdotal reports that portray this as a common behavior among the Lebanese population [27].

In conclusion, there is a need to begin examining globally issues related to the nonmedical use of $\mathrm{PO}$, a behavior that may have seemed specific to North American cultures up to now given the absence of data from other parts of the world. The problem, however, seems more ubiquitous as predicted by a recent United Nations panel [8]. The current study findings, particularly with further replicability, are likely to contribute to the advancement of research (e.g. tweaking the definition of nonmedical use), clinical management of PO users (e.g. better screening and treatment of those who self-treat only vs. at-risk poly- drug users), relevant health policy (e.g. enforcing the proper implementation of sales' regulations), and overall public health (e.g. creating and delivering adequate health and prevention messages to youth as well as their parents about ensuring limited access to such medications without a doctor's recommendation).

\section{Acknowledgements}

The authors would like to extend their gratitude and appreciation to Dr. Sean Esteban McCabe at the University of Michigan for sharing the instrument administered as part of the Student Life Survey. Ms. Reem Saad, Eleine Khoury, and Lynn Itani are also to be thanked for their invaluable assistance in data collection.

The current study was funded by the University Research Board at the American University of Beirut. The American University of Beirut University Research Board had no further role in study design; in the collection, analysis and interpretation of data; in the writing of the report; or in the decision to submit the paper for publication. Dr. Ghandour receives research support from the Ford Foundation, NIH, IDRC, and Swiss Academy for Development. Dr. Martins receives research support from NIH, and NIDA grants DA020667 and DA023434, and NICHD grant HD060072.

\section{Disclosure Statement}

There is no conflict of interest to declare.

\section{References}

$>1$ Compton WM, Volkow ND: Major increases in opioid analgesic abuse in the United States: concerns and strategies. Drug Alcohol Depend 2006;81:103-107.

-2 Kroutil LA, Van Brunt DL, Herman-Stahl MA, Heller DC, Bray RM, Penne MA: Nonmedical use of prescription stimulants in the United States. Drug Alcohol Depend 2006; 84:135-143.

3 McCabe SE, Teter CJ, Boyd CJ: Illicit use of prescription pain medication among college students. Drug Alcohol Depend 2005;77:3747.

$>4$ McCabe SE, Teter CJ, Boyd CJ: Medical use, illicit use and diversion of prescription stimulant medication. J Psychoactive Drugs 2006;38:43-56.

$>5$ Blanco C, Alderson D, Ogburn E, Grant BF, Nunes EV, Hatzenbuehler ML, Hasin DS: Changes in the prevalence of non-medical prescription drug use and drug use disorders in the United States: 1991-1992 and 20012002. Drug Alcohol Depend 2007;90:252260.

6 Catalano RF, White HR, Fleming CB, Haggerty KP: Is nonmedical prescription opiate use a unique form of illicit drug use? Addict Behav 2010;36:79-86.

7 Johnston LD, O’Malley PM, Bachman JG, Schulenberg JE: Monitoring the Future National Survey Results on Drug Use, 19752010. Volume II: College Students and Adults Aged 19-50, 2010. Ann Arbor, Institute for Social Research, University of Michigan, 2010.

$>8$ Zarocostas J: Misuse of prescription drugs could soon exceed that of illicit narcotics, UN panel warns. BMJ 2007;334:444.

$\checkmark 9$ Gilson AM, Ryan KM, Joranson DE, Dahl JL: A reassessment of trends in the medical use and abuse of opioid analgesics and implications for diversion control: 1997-2002. J Pain Symptom Manage 2004;28:176-188.

-10 Zacny J, Bigelow G, Compton P, Foley K, Iguchi M, Sannerud C: College on Problems of Drug Dependence taskforce on prescription opioid non-medical use and abuse: position statement. Drug Alcohol Depend 2003;69: 215-232.

11 Garnier LM, Arria AM, Caldeira KM, Vincent KB, O'Grady KE, Wish ED: Nonmedical prescription analgesic use and concurrent alcohol consumption among college students. Am J Drug Alcohol Abuse 2009;35: 334-338.

12 McCabe SE, Teter CJ, Boyd CJ, Knight JR, Wechsler H: Nonmedical use of prescription opioids among US college students: prevalence and correlates from a national survey. Addict Behav 2005;30:789-805. 
13 McCabe SE, West BT, Cranford JA, Ross-Durow P, Young A, Teter CJ, Boyd CJ: Medical misuse of controlled medications among adolescents. Arch Pediatr Adolesc Med 2011; 165:729-735.

14 Sung HE, Richter L, Vaughan R, Johnson PB, Thom B: Nonmedical use of prescription opioids among teenagers in the United States: trends and correlates. J Adolesc Health 2005;37:44-51.

15 McCabe SE, Cranford JA, Boyd CJ, Teter CJ: Motives, diversion and routes of administration associated with nonmedical use of prescription opioids. Addict Behav 2007;32 562-575.

16 Cone EJ, Fant RV, Rohay JM, Caplan YH, Ballina M, Reder RF, Haddox JD: Oxycodone involvement in drug abuse deaths. II. Evidence for toxic multiple drug-drug interactions. J Anal Toxicol 2004;28:616-624.

-17 Becker WC, Sullivan LE, Tetrault JM, Desai RA, Fiellin DA: Non-medical use, abuse and dependence on prescription opioids among US adults: psychiatric, medical and substance use correlates. Drug Alcohol Depend 2008;94:38-47.

18 Brands B, Paglia-Boak A, Sproule BA, Leslie K, Adlaf EM: Nonmedical use of opioid analgesics among Ontario students. Can Fam Physician 2010;56:256-262.

-19 Fischer B, Nakamura N, Ialomiteanu A, Boak A, Rehm J: Assessing the prevalence of nonmedical prescription opioid use in the general Canadian population: methodological issues and questions. Can J Psychiatry 2010;55:606-609.

20 Haydon E, Rehm J, Fischer B, Monga N, Adlaf E: Prescription drug abuse in Canada and the diversion of prescription drugs into the illicit drug market. Can J Public Health 2005. 96:459-461.

21 Zacny JP, Lichtor SA: Nonmedical use of prescription opioids: motive and ubiquity issues. J Pain 2008;9:473-486.

22 Fredheim O, Magnus S, Log T, Olsen W, Skurtveit $S$, Sagen $\varnothing$, Borchgrevink PC: Prescriptions of opioids to children and adolescents; a study from a national prescription database in Norway. Pediatr Anesth 2010;20: 537-544.
23 Hamunen K, Paakkari P, Kalso E: Trends in opioid consumption in the Nordic countries 2002-2006. Eur J Pain 2009;13:954-962.

24 Ghandour LA, El Sayed DS, Martins SS Prevalence and patterns of commonly abused psychoactive prescription drugs in a sample of university students from Lebanon: an opportunity for cross-cultural comparisons. Drug Alcohol Depend 2011;121:101117.

25 McCabe SE, Boyd CJ, Cranford JA, Teter CJ: Motives for nonmedical use of prescription opioids among high school seniors in the United States: self-treatment and beyond. Arch Pediatr Adolesc Med 2009;163:739_ 744 .

26 Measuring Transparency to Improve Good Governance in the Public Pharmaceutical Sector. Geneva, World Health Organization, 2007.

27 Solberg KE: Lebanese turn to drugs to treat mental-health problems. Lancet 2008;372: 1137-1138.

28 Report of the International Narcotics Control Board on the Availability of Internationally Controlled Drugs: Ensuring Adequate Access for Medical and Scientific Purposes. New York, International Narcotics Control Board, 2010.

29 Harrison L: The validity of self-reported drug use in survey research: an overview and critique of research methods; in Harrison L, Hughes A (eds): The Validity of Self-Reported Drug Use: Improving the Accuracy of Survey Estimates. Rockville, National Institute on Drug Abuse, 1997, pp 17-36.

30 Boyd CJ, Esteban McCabe S, Teter CJ: Medical and nonmedical use of prescription pain medication by youth in a Detroit-area public school district. Drug Alcohol Depend 2006; 81:37-45.

31 McCabe SE, Boyd CJ: Sources of prescription drugs for illicit use. Addict Behav 2005;30: 1342-1350.
32 McCabe SE, Boyd CJ, Teter CJ: Medical use, illicit use, and diversion of abusable prescription drugs. J Am Coll Health 2006;54: 269-278.

33 Stata Statistical Software: Release 12. 2011.

34 McCabe SE, Boyd CJ, Teter CJ: Subtypes of nonmedical prescription drug misuse. Drug Alcohol Depend 2009;102:63-70.

35 Kendler KS, Prescott CA, Myers J, Neale MC: The structure of genetic and environmental risk factors for common psychiatric and substance use disorders in men and women. Arch Gen Psychiatry 2003;60:929-937.

36 Khantzian EJ: The self-medication hypothesis of substance use disorders: a reconsideration and recent applications. Harv Rev Psychiatry 1997;4:231-244.

37 Martins SS, Keyes KM, Storr CL, Zhu H, Chilcoat HD: Pathways between nonmedical opioid use/dependence and psychiatric disorders: results from the National Epidemiologic Survey on Alcohol and Related Conditions. Drug Alcohol Depend 2009;103:1624.

38 Martins SS, Fenton MC, Keyes KM, Blanco C, Zhu H, Storr CL: Mood and anxiety disorders and their association with non-medical prescription opioid use and prescription opioid-use disorder: longitudinal evidence from the National Epidemiologic Study on Alcohol and Related Conditions. Psychol Med 2012;42:1261-1272.

39 Jessor R: Risky driving and adolescent problem behavior: an extension of problem-behavior theory. Alcohol Drugs Driving 1987; 3:1-11.

40 Boyd CJ, Young A, Grey M, McCabe SE: Adolescents' nonmedical use of prescription medications and other problem behaviors. J Adolesc Health 2009;45:543-550.

41 Karam EG, Ghandour L, Maalouf W, Yamout K: Substance Use and Misuse in Lebanon: the Lebanon Rapid Situation Assessment and Response Study. Vienna, UNODC, 2003.

-42 Karam EG, Ghandour LA, Maalouf WE, Yamout K, Salamoun MM: A rapid situation assessment (RSA) study of alcohol and drug use in Lebanon. J Med Liban 2010;58:76-85. 